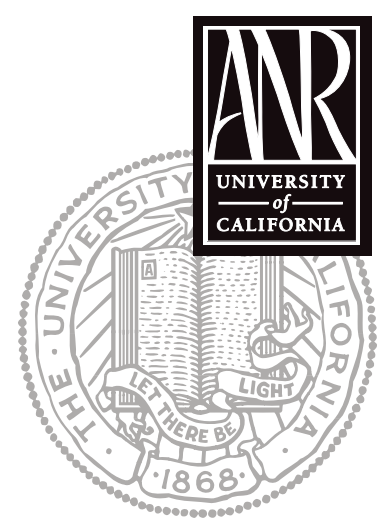

UNIVERSITY OF CALIFORNIA

Division of Agriculture and Natural Resources http://anrcatalog.ucdavis.edu

\title{
Common Lice and Mites of Poultry: Identification and Treatment
}

BRIGID MCCREA, Post-Doctoral Employee, Department of Animal Science, UC Davis; JOAN S. JEFFREY, former Extension Poultry Veterinarian, University of California, Davis; RALPH A. ERNST, Extension Poultry Specialist Emeritus, UC Davis; and ALEC C. GERRY, Assistant Veterinary Entomologist and Extension Specialist, UC Riverside.

Lice and mites are common poultry pests. They feed on the blood, feathers, skin, or scales of the bird. Heavy infestations can result in poor poultry health, reduced growth and egg production, and even the death of birds. Correct identification of the specific louse or mite pest is important to selecting an appropriate treatment regimen.

\section{COMMON POULTRY LICE}

Lice are small (mostly between 1 and $6 \mathrm{~mm}$ [0.04 to $0.24 \mathrm{in}$ ] long), wingless, strawcolored insects with a somewhat flattened appearance and in most cases an elongated abdomen (the hindmost body segment). All poultry lice have chewing mouthparts and feed on dry skin scales, scab tissue, and feather parts. They also feed on blood when the host bird's skin or feather quills are punctured. Lice are commonly found on both the skin and feathers and can move from one bird to another when birds are kept in close contact. The louse's eggs (nits) usually are attached to the feathers.

Lice are ectoparasites and spend their entire life on an animal host. Most louse species are host specific, meaning that they can feed on only one or a few closely related species of animal hosts. Poultry lice cannot survive on humans or on our nonbird domestic pets. In fact, a poultry louse generally completes its entire life cycle from egg to adult on a single bird, and will die within a few days to a week if separated from a host. The number of lice on poultry tend to be greatest during the autumn and winter.

Poultry lice are not known to transmit any avian pathogens, although some wild bird lice are suspected of transmitting pathogens to their hosts. The presence of lice frequently accompanies poor poultry health that is attributable to other causes, and is especially harmful to young birds where high numbers of lice may cause sleep disruption. Effective self-grooming of poultry is an important means of reducing lice. Louse populations are generally higher on birds with injured beaks or on those that have had their beaks trimmed. Molting greatly reduces louse populations, and one effective way to address a severe louse problem is to induce molting and then rapidly remove nit-laden feathers from the poultry facility.

The two most common louse species affecting California poultry are the chicken body louse (Menacanthus stramineus) and the shaft louse (Menapon gallinae). Adult chicken body lice measure 3 to $3.5 \mathrm{~mm}$ ( 0.12 to $0.14 \mathrm{in}$ ) long while adult shaft lice are about $2 \mathrm{~mm}$ (0.08 in) long. Adult chicken body lice are most prevalent around the sparsely feathered vent, breast, and thigh regions. Eggs of the chicken body louse are cemented in clusters to the base of feathers, especially around the vent, while eggs of the shaft louse are cemented individually at the base of the feather shaft or along the feather barb in the breast and thigh regions (Figures 1 and 2). Eggs of both species require 4 to 7 days to hatch and then 10 to 15 days to reach adulthood. An adult louse can lay from 50 to 300 eggs in its 3-week lifespan. 

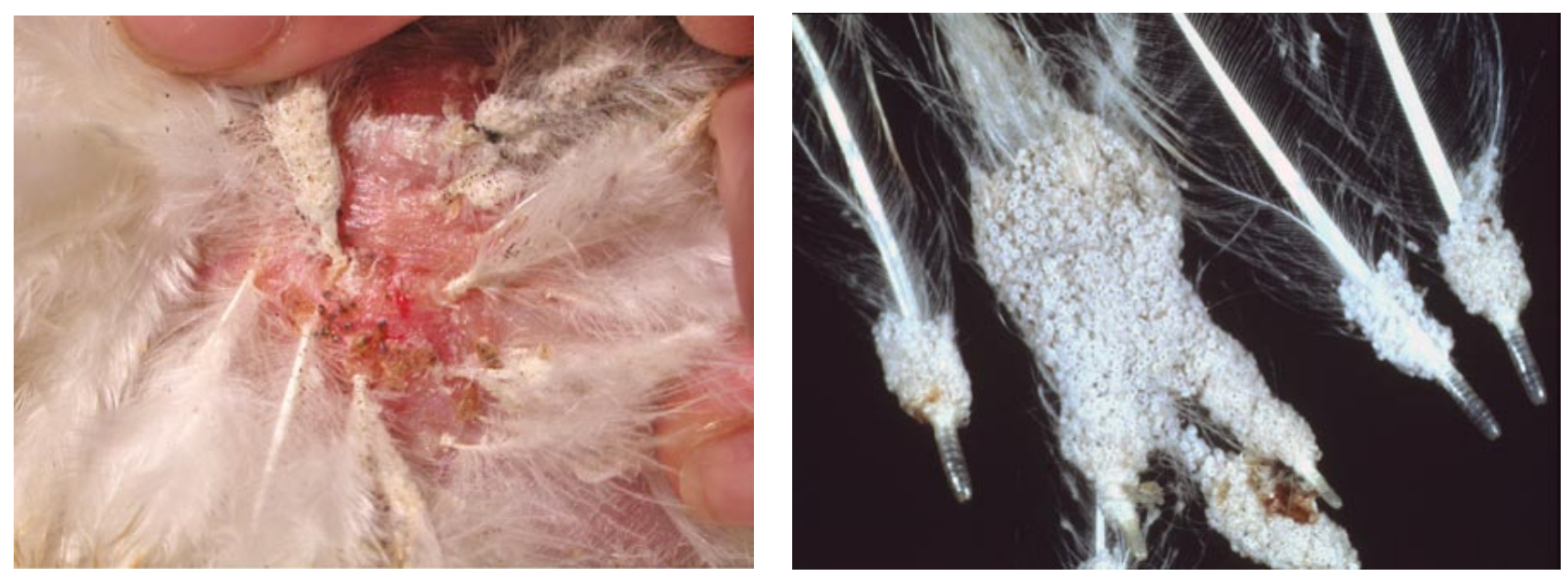

Figures 1 (left) and 2 (right). Egg clusters of the chicken body louse on base of vent feathers. Each egg is less than $1 \mathrm{~mm}$ long. Photos by Nancy Hinkle, University of Georgia (Figure 1) and Brad Mullens, UC Riverside (Figure 2).

Birds should be checked for lice at least twice a month. Examination involves spreading the bird's feathers in the vent, breast, and thigh regions to look for egg clusters or feeding adults at the base of the feathers. The presence of some lice on most birds or of egg clusters on one or more birds is enough to indicate the need for treatment. Chemical treatment, if required, should be applied at 10- to 14-day intervals until the lice and nit numbers fall below this level. Louse eggs are resistant to insecticides, so a single insecticide treatment may not be sufficient to provide control. Louse eggs will subsequently hatch when the insecticide is no longer active. By re-treating at 7- to 10-day intervals, you can kill the newly hatched generation that survived the previous chemical treatment before they can grow to adulthood and lay additional eggs.

\section{COMMON POULTRY MITES}

Mites, too, are very small (just visible without magnification) and may look like dark, moving specks. Like lice, mites are wingless, but in other aspects their body shape is quite different. Besides being much smaller, mites have a generally rounded body shape and lack any obvious body segmentation. Also, mites are arachnids, not insects, so an adult mite has eight legs while an adult louse (an insect) has only six. Mites are not as host specific as lice and may parasitize many animal species. Mites of some species spend their entire life on a single bird, while others are found on the bird only during active feeding periods and retreat to nearby protected locations after feeding. Like lice, mites generally increase in number during the winter months and decrease in the summer.

Chicken mite (or red poultry mite, Dermanyssus gallinae) is a blood-sucking mite that generally feeds on poultry during the night. During the day these mites may be hiding in areas throughout the poultry house, especially in cracks and crevices of surrounding woodwork, under clods of dirt or manure, or in nests. Their habit of leaving the host after nighttime feeding is diagnostic for this mite species. Chicken mites can be red (following a blood meal) to black and can often be found clustered together in the environment surrounding the birds. Usually you have to inspect your birds at night to find them on the skin. Because they need to find daytime hiding places, chicken mites are not generally a pest in cage layer operations, but they can be quite problematic in breeder operations or other situations where fowl are maintained on litter or have nest boxes. Chicken mites have a broad host range and are often associated with a number of wild birds in addition to domestic poultry. 


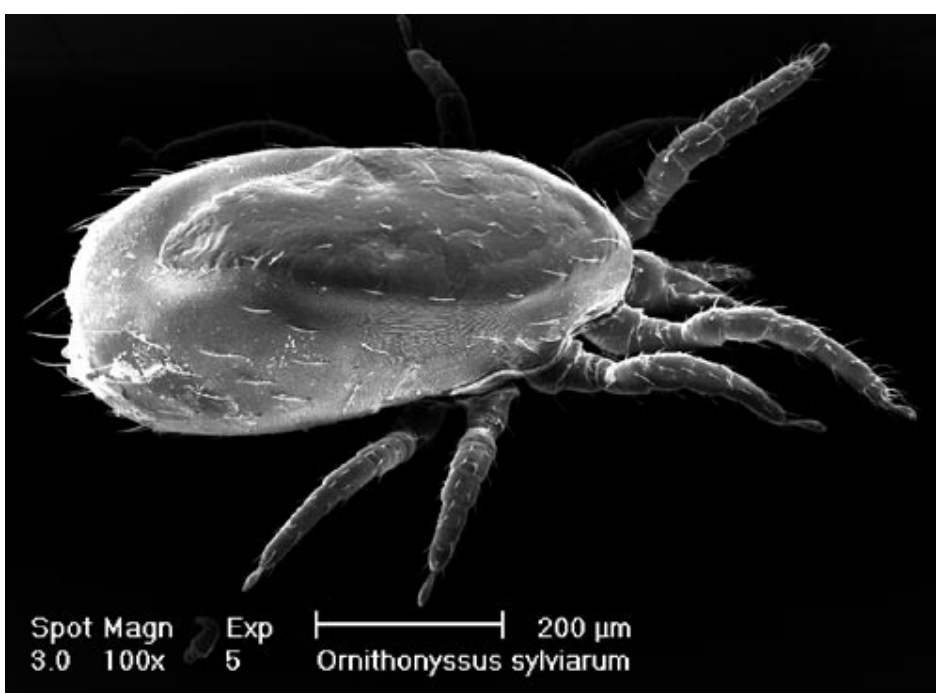

Figure 3. Scanning electron micrograph (SEM) of a northern fowl mite. The scale shows this unfed mite to be slightly less than $1 \mathrm{~mm}$ long. Photo by Jeb Owen, UC Riverside.

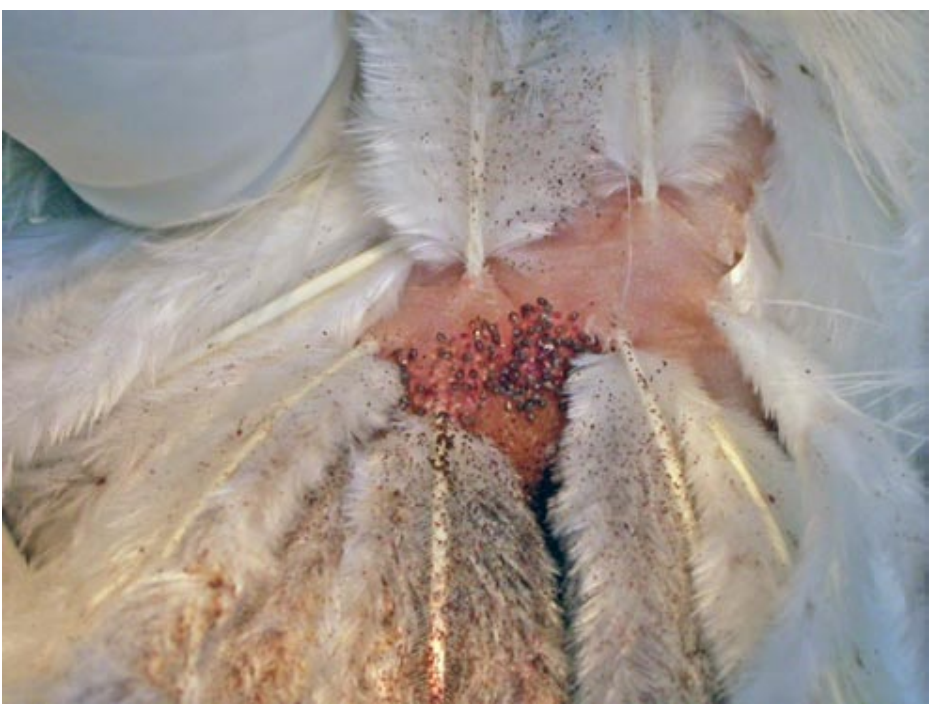

Figure 4. Northern fowl mites feeding on poultry. Photo by Brad Mullens, UC Riverside.
A chicken mite can complete its life cycle in as few as 7 days. Adult females lay small groups of eggs in the environment surrounding their avian host. Eggs hatch in approximately 2 days, and the hatched larvae molt in 1 to 2 days without feeding. At all other life stages, this mite feeds on blood. Adult chicken mites can survive up to 34 weeks of starvation, so they are able to survive long periods where nests or poultry houses are unoccupied. This makes treatment of the entire poultry facility imperative if you want to control this pest.

Because chicken mites feed at night, they rarely bite poultry workers during the workday. Workers who enter an infested poultry house at night, however, will be readily bitten. These bites may be painful, cause irritation and itchiness, and result in small red skin lesions.

The northern fowl mite (Ornithonyssus sylviarum) is a blood-sucking mite that can be found on poultry both day and night (Figures 3 and 4). This mite is commonly found infesting birds in commercial egg-laying facilities throughout California and is arguably the most important external parasite of caged poultry in the state.

Heavy infestations of northern fowl mite are especially costly when your birds are beginning to lay eggs. Northern fowl mites are red to black like chicken mites, but they can be distinguished by their presence during the daytime on poultry, poultry eggs, and cage structures. A heavy infestation of northern fowl mites can result in blackened feathers due to the accumulation of dried blood and excretions, often near the vent, with scabbed and cracked skin around the vent (Figures 5 and 6). Eggs and mites are commonly found under the

Figures 5 (left) and 6 (right). Feather blackening and scabbing, a result of feeding by northern fowl mites. Photos by Brad Mullens, UC Riverside (Figure 5) and Nancy Hinkle, University of Georgia (Figure 6).
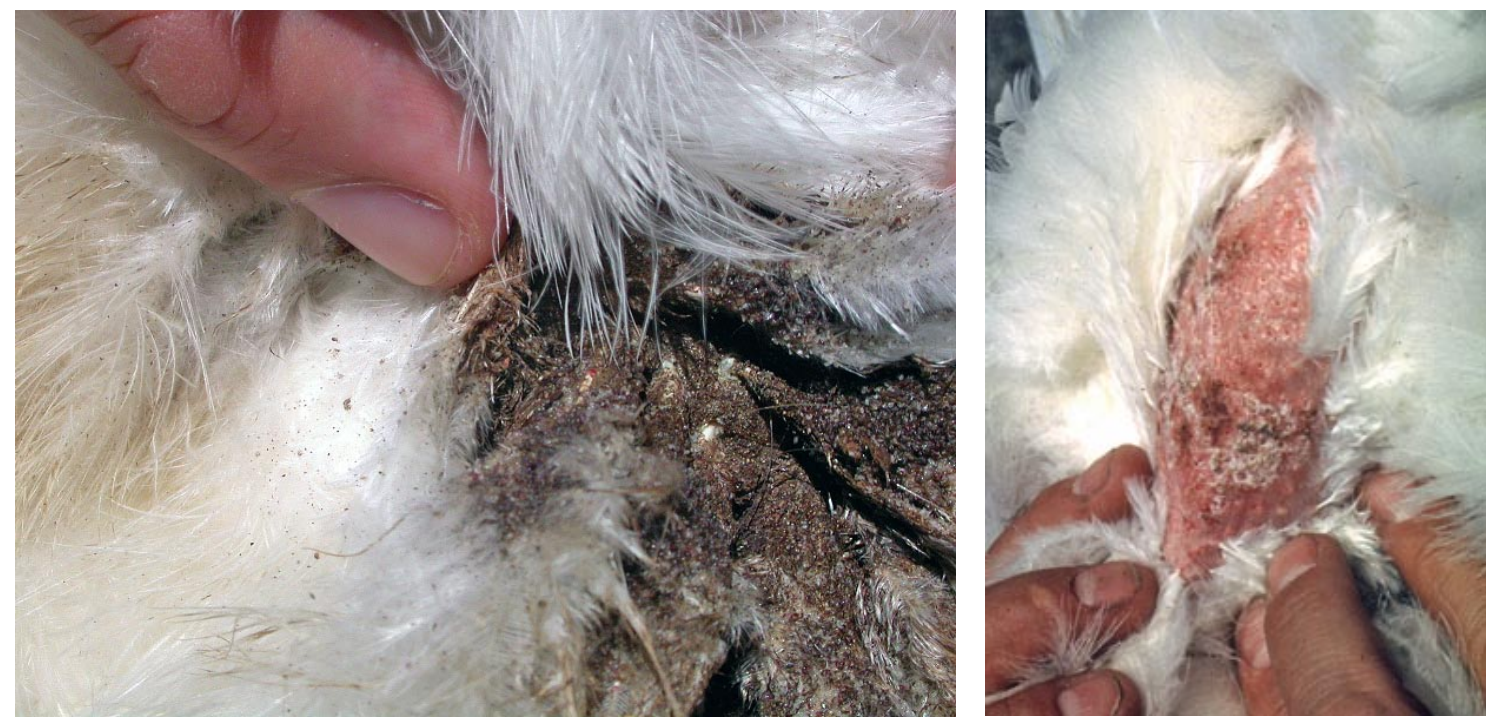
wings, next to the soft feathers of the body, in the feathers above and below the vent, in the beard and crest (on breeds that have them), and on feathers that are high on the legs. If you use a bright flashlight when examining birds for mites, the light will stimulate the mites to move around, making them easier to see. Younger birds generally have more mites than older birds. Northern fowl mites have a broad host range and are often associated with a number of wild birds in addition to domestic fowl.

This mite can complete its life cycle in fewer than 7 days. It has only two bloodfeeding stages, one of which is the adult stage. Adult mites lay white or off-white eggs in bundles on the fluff surrounding the feather shaft. If you find this pest to be present, all birds in the flock should be treated twice, with a 5- to 7-day interval between treatments. An adult northern fowl mite can only survive starvation for up to 2 or 3 weeks, so removal of poultry from an infested facility for more than 3 weeks will result in control.

Because northern fowl mites are active during the day, poultry workers often complain of picking up mites while they handle eggs or birds during the day. These mites only occasionally bite humans. The bite causes a small red skin lesion and intense itching. More importantly, northern fowl mites cause annoyance and concern among poultry workers and their presence may make poultry workers reluctant to continue their work. Many poultry workers wrap their forearms with double-stick tape or spread a Vaseline-like gel on their forearms to capture mites that travel up their arms as they handle mite-infested birds, eggs, or cage structures.

The scaly leg mite (Knemidocoptes mutans) is a very small mite with an oval body and extremely short legs. The mite's entire life cycle is spent burrowing in the unfeathered, scaled skin of a bird's feet and shanks, or occasionally its beak and cere (the fleshy area around its nostrils). Individual birds contract the mites through prolonged, direct contact with other infested birds and infested surroundings. Older birds are the most commonly affected. It is uncommon to find these mites on birds in a commercial operation: commercial poultry are generally young, and they rarely have direct contact with older birds that may be infested with this mite.

Scaly leg mites are too small to see without a microscope. Often, the first indication of parasitism is a brittle, flaky, or powdery appearance to the bird's legs. This may progress to the formation of lesions or scabs, to lumpy, crusty, proliferative masses, and finally to deformation of the shank and crippling of the bird. If you see suspect lesions on a bird's feet and shanks, you can scrape them from the leg, place the scrapings into a small vial, and ship the sample to a veterinary facility for microscopic examination to determine whether these mites are present.

In addition to applying the treatments listed below for chicken mites, you should also isolate or cull birds that are infested with scaly leg mites. If you only have a small number of affected birds, you can treat scaly leg mites by directly applying an oil-based product such as petroleum jelly, a 50:50 kerosene and cooking oil mix, or Blue Ribbon (a commercially available mixture of plant oils and camphor in a canola oil extract). While wearing latex gloves, apply the treatment to the entire affected area once a day for at least 2 weeks. After a few days, the treatment will soften the dead scales and you can gently scrape or rub the dead scales and mites from the bird. Some people report that removal of dead scales by soaking the bird's legs in warm, soapy water before treatment can improve treatment results.

\section{TREATMENT FOR LICE AND MITES}

Pesticides to treat lice and mites are available as dusts, wettable powders, liquid sprays, and resin strips. Dusts and sprays should be applied directly to the birds. When you apply a pesticide to individual birds, part the bird's feathers so the dust or spray will 
reach the skin. For multiple-bird application, use a liquid spray with enough spray pressure to penetrate the feathers and reach the skin. Make sure to spray the birds from below as well as from above to get the best pesticide coverage.

To control chicken mites, you will also need to apply pesticide sprays to litter, bedding, and building structures in order to kill the mites that are hiding in the surrounding environment. When treating building structures, it is best to use a liquid spray so the pesticide will be able to penetrate small cracks and crevices. For poultry kept on litter, you can use a dusting box $(24 \times 36 \times 4$ in $[61 \times 91 \times 10 \mathrm{~cm}])$ containing pesticidal dust for periodic treatment of birds, so long as you do not exceed one treatment every 4 weeks. Pesticidal resin strips placed into poultry cages or nest boxes can provide continuous control of lice and mites. These strips should be placed near food and water sources or roosting sites so the birds will have daily exposure to the strips. Use pesticidal resin strips only during months when you would normally expect louse and mite populations to be high; that way you can delay the development of pesticide resistance and preserve the usefulness of these products. When applying pesticides, always carefully follow the label directions provided with the product and any withdrawal periods required before slaughter of the treated animals.

Read and follow pest control product labels carefully for target pest information, compatibility of the treatment with other management practices, and precautions to avoid contamination of feed, water, meat, or eggs.

At the time of this writing, pesticides that are approved for eliminating lice and mites from poultry and poultry facilities include pyrethrins, synthetic pyrethroids, organophosphates, and a single carbamate (carbaryl or Sevin dust). Remember, though, that pesticide approvals may change, and it's always a good idea to check with your local county agricultural commissioner for current information on approved materials before you apply any pest control chemical. Pyrethrins and synthetic pyrethroids are generally effective and have very low mammalian toxicity. Also, pyrethrins and synthetic pyrethroids are a good choice for use in a chemical rotation program because they are chemically unrelated to the organophosphate and carbamate pesticides traditionally used for mite and louse control. If you rotate the type of pesticide that you use, you can slow the pest's development of pesticide resistance. Northern fowl mite is known to be resistant to both carbaryl and malathion in some parts of California.

If you are treating a small number of birds, Carbaryl dust offers an easy and lowcost treatment option for louse and mite control. Carbaryl is available in a shaker that makes it easy to apply to individual birds. Shaker cans containing Carbaryl are available at most livestock, garden, and hardware stores. A 1-pound package of Carbaryl dust should treat at least 20 chickens.

When treating a flock or a poultry house, the entire flock or house should be treated at the same time to prevent the possibility of rapid re-infestation of treated birds. Once a flock has been treated, it is important that you prevent wild birds or other poultry from contacting the flock and causing new infestations. 


\section{FOR MORE INFORMATION}

You will find related information in these titles and in other publications, slide sets, CD-ROMs, and videos from UC ANR:

Egg Candling and Breakout Analysis, Publication 8134

Poultry Planned Disease Prevention Series, Publication ANRP005

Selecting Chickens for Home Use, Publication 7232

To order these products, visit our online catalog at http://anrcatalog.ucdavis.edu. You can also place orders by mail, phone, or FAX, or request a printed catalog of publications, slide sets, CD-ROMs, and videos from

University of California

Agriculture and Natural Resources

Communication Services

6701 San Pablo Avenue, 2nd Floor

Oakland, California 94608-1239

Telephone: (800) 994-8849 or (510) 642-2431

FAX: (510) 643-5470

E-mail inquiries: danrcs@ucdavis.edu

An electronic version of this publication is available on the ANR Communication Services Web site at http://anrcatalog.ucdavis.edu.

\section{Publication 8162}

This publication has been anonymously peer reviewed for technical accuracy by University of California scientists and other qualified professionals. This review process was managed by the ANR Associate Editor for Animal, Avian, Aquaculture, and Veterinary Sciences.

(C)2005 by the Regents of the University of California

Division of Agriculture and Natural Resources.

All rights reserved.

To simplify information, trade names of products have been used. No endorsement of named products is intended, nor is criticism implied of similar products that are not mentioned.

The University of California prohibits discrimination or harassment of any person on the basis of race, color, national origin, religion, sex, gender identity, pregnancy (including childbirth, and medical conditions related to pregnancy or childbirth), physical or mental disability, medical condition (cancer-related or genetic characteristics), ancestry, marital status, age, sexual orientation, citizenship, or status as a covered veteran (covered veterans are special disabled veterans, recently separated veterans, Vietnam era veterans, or any other veterans who served on active duty during a war or in a campaign or expedition for which a campaign badge has been authorized) in any of its programs or activities.

University policy is intended to be consistent with the provisions of applicable State and Federal laws.

Inquiries regarding the University's nondiscrimination policies may be directed to the Affirmative Action/Staff Personnel Services Director, University of California, Agriculture and Natural Resources, 300 Lakeside Drive, $6^{\text {th }}$ Floor, Oakland, CA 94612-3550, (510) 987-0096. For information about obtaining this publication, call (800) 994-8849. For downloading information, call (530) 297-4445.

pr-11/05-WJC/CR

ISBN 978-1-60107-331-0 
7 ANR Publication 8162

\section{COMMON POULTRY LICE}

Figures 1 (left) and 2 (right). Egg clusters of the chicken body louse on base of vent feathers. Each egg is less than 1 mm long. Photos by Nancy Hinkle, University of Georgia (Figure 1) and Brad Mullens, UC Riverside (Figure 2).

\section{COMMON POULTRY MITES}

Figure 3. Scanning electron micrograph (SEM) of a northern fowl mite. The scale shows this unfed mite to be slightly less than $1 \mathrm{~mm}$ long. Photo by Jeb Owen, UC Riverside.

Figure 4. Northern fowl mites feeding on poultry. Photo by Brad Mullens, UC Riverside.

Figures 5 (left) and 6 (right). Feather blackening and scabbing, a result of feeding by northern fowl mites. Photos by Brad Mullens, UC Riverside (Figure 5) and Nancy Hinkle, University of Georgia (Figure 6).

\section{TREATMENT FOR LICE AND MITES}

\section{FOR MORE INFORMATION}

